\title{
O Sonhar Social: Uma Experiência no Brasil
}

\author{
Roque Tadeu Gui \\ Vera Lúcia Decnop Coelho ${ }^{1}$ \\ Universidade de Brasília
}

\begin{abstract}
RESUMO - A matriz do sonhar social é um dispositivo criado com a finalidade de apreender o significado social dos sonhos. Buscamos avaliar sua aplicação no contexto brasileiro e cogitamos sobre suas potencialidades em processos de intervenção psicológica. Foram realizados encontros de compartilhamento de sonhos com dois grupos: 14 profissionais de gestão de pessoas de uma instituição financeira nacional e seis psicólogos formandos e recém-formados de uma universidade pública federal. Utilizamos a técnica de observação participante e questionários de avaliação de reação, procedendo à avaliação qualitativa das informações. Constatamos a aplicabilidade do dispositivo e formulamos hipótese sobre a utilização da matriz em intervenção psicológica.
\end{abstract}

Palavras-chave: matriz do sonhar social, relato do sonho, conteúdo do sonho, análise do sonho

\section{Social dreaming: An experience in Brazil}

\begin{abstract}
The social dreaming matrix is a device created for the purpose of grasping the social meaning of dreams. We tried to evaluate its application in the context of Brazil and theorized about its potential in processes of psychological intervention. Meetings were held to share dreams with two groups: 14 human management professionals of a national financial institution and six trainees and graduates in Psychology of a federal public university. The information gathered with the technique of participant observation and reaction evaluating questionnaires was interpreted using qualitative methods. The applicability of the device was verified and a hypothesis was formulated about the use of the matrix in psychological intervention.
\end{abstract}

Keywords: social dreaming matrix, dream recall, dream content, dream analysis

O sonhar social (social dreaming) é um método de compartilhamento de sonhos individuais em grupo, com o propósito de encontrar relações entre os sonhos e conectá-los às circunstâncias sociais dos sonhadores. Desenvolvido a partir da década de 1980 por meio dos estudos de Lawrence e colaboradores, associados ao Instituto de Relações Humanas de Tavistock, Reino Unido (Lawrence, 1991), procura resgatar a visão tradicional do sonhar como algo que fazia parte do discurso conversacional da vida cotidiana, tal como tem sido documentado por antropólogos culturais (Tedlock, 1987, 1991), e estudado por pesquisadores interessados em processos grupais, grupoanálise e análise institucional (e.g. Lawrence, 1991, 1998a, 2003, 2005, 2007a, 2007b; Michael, 1998, 2007; Morgan, 2007; Neri, 2003) e, mais recentemente, em psicologia clínica (Gui, 2010).

Com base na teoria comunicacional sobre o sonhar, proposta pela antropologia cultural (Tedlock, 1991), elaboramos uma definição operacional para o construto "sonhar social": sequência processual que envolve: a) o compartilhamento de sonhos individuais, b) as associações livres dos participantes, c) as conexões entre sonhos, d) a identificação de padrões associativos, e) a emergência de significados sociais. A definição permite maior clareza quanto ao que queremos dizer ao nos referirmos ao sonhar social.

1 Endereço para correspondência: Universidade de Brasília, Instituto de Psicologia, Departamento de Psicologia Clínica, Campus Universitário Darcy Ribeiro, Brasília, DF, CEP 70910-900

E-mail: veradecnop@gmail.com
O interesse pela identificação de dispositivos orientados para a apreensão das circunstâncias comuns e compartilhadas de um grupo, e que favoreçam a elaboração conjunta (produção de pensamentos), retroagindo concomitantemente sobre a subjetividade dos indivíduos, direcionou-nos para a pesquisa do sonhar social e, em particular, para a experiência prática com a "matriz do sonhar social", proposta por Lawrence (1998a, 2003, 2005, 2007b) e Neri (2003), dentre outros.

O sonhar social vem sendo utilizado em estratégias de intervenção organizacional, institucional e grupal, muitas delas associadas à metodologia de pesquisa-ação (Lawrence, 1998b), favorecendo a tomada de consciência de aspectos olvidados, despercebidos, ou fracamente percebidos do ambiente social. O método tem sido testado em diversos países, tais como, Áustria, Israel, África do Sul, Itália, Austrália (por exemplo, Amitzi, 2007; Marinelli \& Girelli, 2007; Sievers, 2007; Neri, 2003), e mais recentemente, no Brasil (Gui, 2010). Não há referências, contudo, à utilização no contexto de processos clínicos psicoterapêuticos.

Dado o pouco conhecimento a respeito do sonhar social no Brasil, optamos por um estudo exploratório qualitativo, mediante a aplicação da "matriz do sonhar social" e do seu complemento, o "diálogo de reflexão sobre sonhos", nos moldes previstos pela literatura científica sobre o assunto (Lawrence, 1998a, 2003, 2005, 2007b; Neri, 2003), confrontando os resultados com "hipóteses de trabalho" que vêm utilizadas pelos teóricos do sonhar social. Esses autores têm preferido referir-se aos achados decorrentes de sua experimentação como hipóteses de trabalho que, se reiteradamente 
confirmadas por outros trabalhos, tais como este estudo, acabarão por constituir elementos para a construção de uma teoria sobre o sonhar social.

\section{Funcionamento da Matriz do Sonhar Social}

Lawrence (1998a) desenvolveu a "matriz do sonhar social" como dispositivo para apreender o sentido social dos sonhos. Pessoas se reúnem voluntariamente para narrar sonhos, apresentar associações, articular os sonhos apresentados, amplificar temas que emergem do processo associativo, ou seja, relacioná-los com outros aspectos sociais, políticos ou culturais, e buscar significados sociais.

O arranjo das cadeiras é feito em forma de "floco de neve" (Figura 1), evitando que os participantes fiquem diretamente face a face. Procura-se com isso romper o padrão de interação grupal usualmente conhecido. Supostamente, essa disposição ajuda a criar um ambiente mais livre de pensamento, centrado nos sonhos e não nas relações interpessoais.

Os facilitadores se distribuem e assentam-se entre os participantes. A instrução básica para o início do trabalho na matriz é: "A tarefa principal é fazer associações o mais livremente possível com seus próprios sonhos e com os sonhos dos outros apresentados na matriz, a fim de criar as ligações e encontrar as conexões entre os sonhos. Quem tem o primeiro sonho?"

Um participante narra um sonho que pode ser seguido imediatamente por outro sonho ou por uma associação livre de um dos participantes. O facilitador ouve a narrativa do sonho e tenta discernir os temas que estão contidos na história, informação importante para ser utilizada na segunda etapa do trabalho.

$\mathrm{O}$ facilitador encarrega-se de fazer respeitar as regras do enquadre (Lawrence, 1998a, 2005; Neri, 2003). Deixa aos participantes a tarefa de associar, de buscar as significações e de identificar alegorias e símbolos. Ele intervém para facilitar o trabalho, mas não propõe interpretações relativas à dinâmica do grupo ou à formação de subgrupos. Suas intervenções são totalmente balizadas por aquilo que está evidente. Nos primeiros encontros, notadamente, pode ser

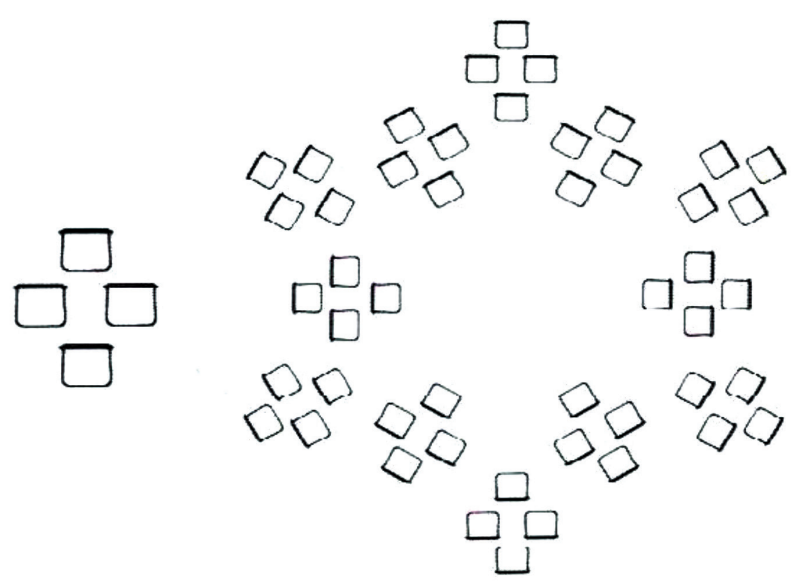

Figura 1. Diagrama do arranjo das cadeiras para a Matriz do Sonhar Social (Lawrence, 2005, p. 96). necessário explicar aos participantes o modelo do sonhar social, que é abstrato e de compreensão não imediata. $\mathrm{O}$ facilitador pode estimular ocasionalmente o participante a agregar uma associação ao sonho que ele mesmo narrou. Por vezes, pode solicitar também que ofereçam associações a uma imagem ou a uma palavra determinada que aparece em um sonho. Se um participante começar a interpretar, dirigindo a atenção para o sonhador, ao invés de se ater ao sonho, o facilitador procura estimulá-lo a retornar à tarefa da matriz.

Concluída a etapa de compartilhamento de sonhos, com associações e amplificações, os participantes da matriz do sonhar social são convidados para o grupo de reflexão sobre os sonhos, cuja tarefa será identificar os sonhos que foram narrados, as ligações entre os sonhos, os temas sociais que surgiram, ou seja, temas que remetem às circunstâncias sociais vividas pelos sonhadores, e aspectos emergentes (novas possibilidades) nos sistemas sociais (grupo profissional, organização, instituição, família) dos quais participam.

$\mathrm{O}$ presente estudo tem por objetivo geral investigar a matriz do sonhar social no contexto brasileiro, e como objetivos específicos: a) aplicar a matriz do sonhar social com dois grupos; b) avaliar a experiência na perspectiva do pesquisador e dos participantes; c) confrontar a experiência de trabalho na matriz com as "hipóteses de trabalho" que têm norteado os trabalhos de outros pesquisadores; d) conjecturar sobre as potencialidades do sonhar social para o trabalho de intervenção psicológica.

\section{Metodologia}

\section{Corpora}

Adotamos para o presente estudo o conceito de corpus (plural: corpora) de pesquisa proposto por Bauer e Aarts (2002). Os autores, citando Barthes (1967), definem corpus como "uma coleção finita de materiais, determinada de antemão pelo analista, com (inevitável) arbitrariedade, e com a qual irá trabalhar" (p. 44). A escolha, contudo, respeita critérios racionais alternativos àqueles adotados na amostragem estatística aleatória.

No presente estudo, a "coleção finita de materiais" consiste nos textos originados da degravação de encontros do sonhar social realizados com sujeitos selecionados pelo pesquisador, segundo critérios que veremos adiante. Seguimos a perspectiva metodológica de Bauer e Aarts (2002) para a construção racional de um corpus, adotando os critérios de relevância, homogeneidade e sincronicidade do material escolhido.

$\mathrm{O}$ critério de relevância exige que o material recolhido refira-se especificamente ao tema estudado e não a qualquer outro; homogeneidade refere-se à substância material dos dados, por exemplo, não se misturando materiais textuais com materiais visuais; sincronicidade relaciona-se com o momento em que o material foi colhido, levando-se em conta o seu ciclo natural de estabilidade e mudança; define, portanto, o intervalo de tempo dentro do qual um corpus de material relevante e homogêneo deve ser selecionado. A construção do corpora do presente estudo atendeu a essas exigências: os textos examinados (um para cada encontro realizado) 
referem-se a narrativas de sonhos, associações realizadas pelos sujeitos, intervenções do facilitador e elaborações de sínteses temáticas (relevância). O registro em vídeo foi utilizado unicamente para a identificação dos sujeitos e melhor compreensão das respectivas falas (homogeneidade). $\mathrm{O}$ material de cada corpus foi recolhido em um número limitado de encontros (três ou quatro, conforme o grupo), realizados em intervalos de no máximo uma semana entre um e outro (sincronicidade).

Não buscamos a "saturação informacional". Segundo os autores, "saturação é o critério de finalização da investigação: investigam-se diferentes representações apenas até que a inclusão de novos estratos não acrescente mais nada de novo" (p. 59). Contudo, ao realizar o número de três encontros, no caso de um dos grupos, ou quatro, no de outro, conseguimos certo grau de saturação de informações nos espaços sociais especificamente estudados.

Do exposto, depreende-se que o estudo revestiu-se de caráter exploratório e não pretendemos, na seleção dos participantes, obter uma representação da totalidade do estrato do qual os sujeitos fazem parte; buscamos, sim, a caracterização, compreensão e interpretação dos fenômenos observados nos dois grupos estudados.

\section{Participantes}

O conjunto de informações (corpora da pesquisa) foi construído a partir de dois corpus distintos, tendo como fonte participantes escolhidos por conveniência, segundo critérios relacionados com o espaço social que ocupam, descritos a seguir:

\section{Grupo I - profissionais de gestão de pessoas}

As informações do primeiro corpus foram fornecidas por 14 profissionais da área de gestão de pessoas de uma instituição financeira nacional (10 mulheres e quatro homens, com idades entre 30 e 52 anos, média de 44,6 anos), convidados a participar de três encontros, com periodicidade semanal. A matriz do sonhar social tem sido aplicada em encontros únicos ou em vários encontros sucessivos (Lawrence, 2005; Neri, 2003); para nossos propósitos, julgamos que o número de três ou quatro encontros seria suficiente.

Interessou aos pesquisadores realizar experiência com pessoas que, compartilhando um mesmo ambiente social - uma organização financeira fortemente estruturada - não estivessem vivenciando um momento de crise claramente identificável. Imaginamos que os temas sociais emergentes estariam conectados às circunstâncias organizacionais vivenciadas pelos participantes. De agora em diante, esse grupo é denominado "Grupo Gestão".

Embora tivéssemos planejado que o grupo fosse formado por seis participantes que permaneceriam durante os três encontros, isso não ocorreu devido a dificuldades na liberação dos profissionais durante a jornada de trabalho. Assim, alguns dos participantes originais foram substituídos por outros voluntários ao longo dos encontros, totalizando, ao final da experiência, 14 participantes. Destes, dois estiveram em todos os encontros; cinco participaram de dois encontros e sete de apenas um encontro. Os encontros foram realizados no ambiente organizacional, em sala especialmente reservada para o evento.

\section{Grupo II - psicólogos formandos e recém-formados}

As informações que constituíram o segundo corpus foram fornecidas por seis formandos (cursando o último semestre) $\mathrm{e}$ recém-formados (nos últimos seis meses) do curso de psicologia de uma universidade pública federal (quatro mulheres e dois homens, com idades entre 22 e 27 anos, média de 23,7 anos), convidados a participar de quatro encontros do sonhar social, com periodicidade semanal.

Interessou aos pesquisadores aplicar o dispositivo com indivíduos que estivessem vivenciando momento supostamente crítico relacionado com a assunção de um novo papel profissional (psicólogo). Dadas as características desse público - recém-formados e formandos em psicologia - interessava observar como jovens habituados à visão psicológica-interpretativa dos sonhos reagiriam diante de um dispositivo que requer contenção na análise psicológica individual para dar destaque a temas emergentes que remetem às circunstâncias sociais dos participantes. Esperávamos poder observar aspectos relacionados ao momento crítico vivido pelos participantes que pudessem suscitar conjecturas sobre a utilização da matriz do sonhar social como dispositivo de intervenção psicológica. Apenas uma participante precisou faltar a um encontro, em virtude de compromisso acadêmico. Os encontros foram realizados no Centro de Atendimento e Estudos da Universidade, em sala especialmente destinada ao evento. De agora em diante, esse grupo é denominado "Grupo Psi".

O projeto de pesquisa foi avaliado e aprovado pelo Comitê de Ética em Pesquisa com Seres Humanos do Instituto de Ciências Humanas da Universidade de Brasília. Os participantes receberam carta-convite com as principais informações sobre os encontros e assinaram Termo de Consentimento Livre e Esclarecido para a participação na pesquisa. Protegeu-se o sigilo sobre a identidade dos participantes, adotando-se, na versão textual das informações, nomes fictícios.

\section{Coleta de Informações}

Realizamos "encontros do sonhar social", com duração de uma hora a uma hora e meia, nos moldes propostos por Lawrence (1998a, 2003). Os encontros foram conduzidos pelo primeiro autor deste artigo. Registramos, em áudio e vídeo, as narrativas dos sonhos individuais, as séries associativas e as amplificações temáticas oferecidas para cada sonho, a disposição afetiva dos participantes em face da tarefa a ser realizada, as sínteses elaboradas pelos grupos, a identificação de temas sociais emergentes e a atuação do facilitador.

\section{Procedimentos}

Os encontros foram conduzidos em etapas: 1) o facilitador explicou a natureza do trabalho a ser realizado; 2) solicitou que um voluntário apresentasse um sonho; 3) após 
a narrativa do sonho, o facilitador solicitou aos participantes que oferecessem associações ao sonho narrado; 4) após certo período de tempo (aproximadamente 45 minutos), o facilitador iniciou o "diálogo reflexivo sobre os sonhos", durante outros 45 minutos, com vistas a identificar os temas recorrentes sugeridos pelas associações.

\section{Instrumentos}

Com o intuito de obter informações a respeito das percepções dos participantes sobre o trabalho realizado, aplicamos, para o Grupo Gestão, o instrumento de Avaliação de Reação Final (Anexo B), ao término do $3^{\circ}$ encontro. Para o Grupo Psi, foram aplicados o instrumento de Avaliação de Reação Parcial (Anexo A), ao final do $2^{\circ}$ encontro, e o instrumento de Avaliação de Reação Final (Anexo B), ao término do $4^{\circ}$ encontro. Nesse caso, pretendemos verificar eventuais mudanças nas reações dos participantes no decurso dos encontros.

\section{Tratamento das Informações}

Organizamos e analisamos os dois corpus textuais gerados a partir da degravação dos registros de áudio e vídeo. As informações obtidas por meio de áudio foram enriquecidas pelo material de vídeo, às vezes para esclarecer o sentido da verbalização, outras para detectar-se o tom emocional do depoimento (rações de espanto, humor, ironia); o corpus procurou abranger tais informações. Os nomes adotados na versão textual são fictícios, respeitando-se a caracterização de gênero do participante.

As narrativas oníricas foram integralmente preservadas e sofreram apenas pequenos ajustes de edição. As associações de cada um dos sonhos foram recortadas e resumidas, preservando-se o seu núcleo de sentido (imagens, ideias, emoções). O mesmo tratamento foi dado às informações geradas pelo diálogo reflexivo sobre os sonhos (recorte, resumo e redução às unidades de sentido), inclusive no que diz respeito à transcrição integral de eventuais falas (Laville \& Dione, 1999).

\section{Análise das Informações}

Adotamos o método de análise de conteúdos segundo revisão da literatura efetuada por Bauer (2002). De acordo com o autor, a validade da técnica a ser utilizada deve ser julgada em termos de sua "fundamentação nos materiais pesquisados e sua congruência com a teoria do pesquisador, e à luz de seu objetivo de pesquisa. Um corpus de texto oferece diferentes leituras, dependendo dos vieses que ele contém" (Bauer, 2002, p. 191). Buscamos, então: a) descrição objetiva, sistemática do conteúdo manifesto da comunicação; b) inferência através da identificação objetiva e sistemática de características específicas de mensagens; c) processamento da informação em que o conteúdo da comunicação é transformado, através da aplicação objetiva e sistemática de regras de categorização; d) produção de inferências replicáveis e práticas partindo dos dados em direção a seu contexto (Berelson, Holsti, Paisley, Krippendorff, citados por Bauer, 2002).

Tratamos cada um dos sonhos e respectivas associações como uma unidade temática; dedicamos atenção especial à interligação dos sonhos e das associações realizadas, assim como às intervenções do facilitador. Ao final de cada encontro, consideramos o conjunto de todos os sonhos e suas associações como uma totalidade, procurando, por meio do exame das informações originadas pelo diálogo reflexivo sobre os sonhos, identificar a unidade temática afetiva e social, ancorando-a em alguma dimensão social relevante para o grupo.

Buscamos uma "construção iterativa [repetida, reiterada] de explicação", progredindo por aproximações sucessivas (Laville \& Dione, 1999, p. 227). A explicação que emergiu é resultado do exame: a) das unidades de sentido (associações, amplificações); b) das interrelações dessas unidades (séries associativas dos sonhos); c) das categorias nas quais essas unidades se reúnem (universo associativo e temas-síntese); d) das informações obtidas por meio dos instrumentos de avaliação de reação aos encontros, parcial e final. Por fim, comparamos os resultados da experiência com as hipóteses de trabalho usualmente utilizadas pelos teóricos do sonhar social.

\section{Resultados e Discussão}

\section{Considerações Gerais sobre a Aplicação do Sonhar Social}

A partir das avaliações de reação, verificamos que a experiência com a matriz do sonhar social foi percebida como agradável e produtiva, propiciando aos participantes novas perspectivas sobre a realidade social na qual estão inseridos, mais especificamente, o contexto organizacional no qual trabalham (Grupo Gestão) e o contexto socioprofissional e familiar (Grupo Psi).

Os participantes demonstraram compreender a tarefa proposta para o encontro - narrar sonhos, fazer associações, estabelecer ligações entre sonhos, encontrar nexos e atribuir significado social, bem como a "regra fundamental": evitar incursionar por interpretações psicológicas, biográficas ou relacionadas à dinâmica psicológica do grupo. Ocorreram apenas dois momentos, durante o trabalho com o Grupo Psi, em que o facilitador precisou intervir para esclarecer a diferença entre apresentar associações e fazer interpretação psicológica do sonho.

Observamos que, em ambas as experiências, a matriz assumiu as características de "grupo de trabalho", na acepção adotada por Bion (1963/2006a), ou seja, um grupo que focaliza a tarefa a ser realizada mediante laços cooperativos. Os participantes envolveram-se ludicamente no processo associativo, manifestando motivação, humor, muitas vezes ironia, e capacidade reflexiva. Observamos um incremento da atividade associativa à medida que os encontros ocorriam.

A disposição dos participantes em configuração "floco de neve" (Figura 1), com vistas a dificultar a indução de um processo de análise grupal, conforme previsto por Lawrence (2003), revelou-se, no Grupo Gestão, mais dificultadora do 
que facilitadora do trabalho, gerando certo desconforto, talvez por se tratar de um grupo pequeno constituído por pessoas que se conhecem. Grupos maiores, como os reportados nos estudos do sonhar social, com 20 ou mais participantes, talvez aceitem mais facilmente o formato "floco de neve". No Grupo Psi o trabalho ocorreu satisfatoriamente com os participantes dispostos em formato de arco, decisão tomada a partir da experiência com o Grupo Gestão.

Embora alguns dos sonhos apresentados - sobretudo no primeiro encontro do Grupo Psi - tenham sido sonhados em períodos anteriores à época de realização da matriz, pareceu-nos que a vivência na matriz favoreceu cada vez mais a lembrança de sonhos recentes que foram trazidos para o trabalho. Os sonhos surgiram uns após outros, como decorrência do processo associativo, confirmando experiências de encadeamento associativo relatadas em outros trabalhos (Lawrence, 1998a, 2007).

A mobilização dos integrantes na primeira etapa do trabalho - narrar sonhos, associar, fazer conexões - mostrou-se relacionada a certo caráter lúdico apresentado por esse tipo de atividade, um jogo espontâneo que envolve contar sonhos e deixar a imaginação livre para associar. Já no diálogo reflexivo sobre os sonhos, a participação ativa dos sujeitos parece ter se vinculado ao fato de discutirem uma realidade que lhes é próxima e carregada de sentido. Os participantes envolvem-se à medida que percebem a emergência de conexões dos sonhos com a realidade vivida.

Pelo exame das gravações em áudio e vídeo, pudemos constatar que o facilitador adotou comportamento caracterizado, de modo geral, pela contenção: evitou fazer associações; focalizou a compreensão e o cumprimento das regras de funcionamento da matriz; ofereceu amplificações oportunas e pontuou associações.

No entanto, no "diálogo reflexivo sobre os sonhos", sua atuação apresentou sensíveis diferenças: no Grupo Gestão, limitou-se a refletir sentimentos, fazer ampliações temáticas e sintetizar reflexões; no Grupo Psi, além dessas tarefas, ofereceu informações e opiniões sobre os temas e questões apresentadas, configurando uma atuação mais interventiva, própria da pesquisa-participante. A experiência com os dois grupos evidenciou, então, diferentes possibilidades de condução do dispositivo, em função da composição do grupo e dos objetivos pretendidos. As sínteses emergentes se conectaram com o momento crítico vivido pelos participantes e parecem ter favorecido insights interessantes para a compreensão dessas circunstâncias.

Certo cuidado é requerido nos casos em que novos participantes se agregam à matriz, para que possam compreender claramente a dinâmica do sonhar social, já assimilada pelos demais. Parece-nos que se, por um lado, a manutenção da composição original do grupo pode representar uma vantagem para assegurar uma compreensão homogênea das regras pelos participantes, por outro, a variação dos membros pode trazer maior complexidade e abrangência do contexto social no qual o grupo vive.

Nossa experiência demonstrou o cuidado que se deve ter com a interrupção do processo associativo, decorrente da ansiedade do grupo em discutir prematuramente ideias que emergem nas associações, evitando-se que ocorra um abortamento do processo imaginativo grupal. De fato, o cerne do método consiste em utilizar sonhos pessoais para revelar, por meio do processo associativo grupal, o seu enraizamento social. Um "ataque" reflexivo muito rápido sobre o material associativo interrompe o fluxo de ideias que podem representar uma abertura nos filtros dos conceitos, da língua, da lógica e dos costumes sociais, que impedem a tomada de consciência de material inconsciente (Fromm, Suzuki, \& Martino, 1970; Hopper, 2003).

\section{Análise da Experiência do Grupo Gestão}

É importante ressaltar que este grupo foi constituído por profissionais habituados à reflexão, análise e discussão sobre aspectos organizacionais, o que deve ter facilitado o processo de transição dos sonhos e associações para o exame da realidade social.

Observamos que certos sonhos apresentaram-se como fortes atratores associativos, catalisando a atenção do grupo e favorecendo o salto para a análise das circunstâncias sociais. Atribuímos a estes a denominação "sonhos-atrator", ou seja, sonhos que constelam aspectos críticos da existência social dos participantes, levando-os a produzir grande número de associações, estabelecer conexões entre sonhos e aspectos do real vivido, e incorporar as imagens oníricas da matriz à linguagem do próprio grupo.

Outro aspecto interessante que surgiu da experiência com o Grupo Gestão foi a amplificação de temas por meio de referência a filmes, caracterizando-os como "filmes-sonho", que apresentam a característica de, ao serem referidos, prolongar o estado oniróide propiciado pelo processo associativo. O cinema, tal como outras formas de arte (literatura e artes plásticas, por exemplo), é uma expressão cultural que parece favorecer o sonhar social, qualidade com interessante potencial a ser explorado.

Aspectos do ambiente organizacional no qual trabalham os profissionais ganharam destaque. Temas sociais mais amplos - tais como a violência nas cidades e questões sociopolíticas, embora tenham surgido, perderam relevância diante da realidade do dia a dia profissional dos participantes. Surgiram temas relacionados com a restrição à criatividade no ambiente de trabalho, a falta de liberdade para inovar, o desafio de promover mudanças e a crise de identidade profissional.

A partir das associações, amplificações e sínteses, o Grupo Gestão chegou à formulação de dois temas-síntese - "Como ser criativo diante dos limites colocados pela Organização?" e "Como lidar com o novo?" - que poderiam gerar ações para a mudança organizacional, apontando para um possível projeto coletivo. A formulação dos temas-síntese constituiu-se questão-chave do diálogo reflexivo sobre os sonhos.

$\mathrm{Na}$ avaliação de reação, o Grupo Gestão relatou benefícios psicológicos pessoais relacionados com o exercício profissional: a oportunidade de aprender uma metodologia de trabalho que possibilita perceber e observar comportamentos organizacionais "camuflados", a oportunidade de discutir as relações profissionais, além do prazer de participar, de ouvir o outro, de conhecer opiniões diferentes e ouvir pontos de vista diversos sobre os seus próprios sonhos. 


\section{Análise da Experiência do Grupo Psi}

Tal como no grupo anterior, aqui também surgiram sonhos que propiciaram grande quantidade de associações e que apontaram para temas fortemente vinculados às circunstâncias sociais dos participantes (sonhos-atrator).

Embora também tenham surgido temas fortemente orientados por vivências pessoais (fim de uma etapa vital, insegurança em relação às mudanças identitárias, desafios de assumir uma profissão, ansiedades em relação ao desligamento familiar e à busca de autonomia pessoal), destacou-se um fundo de questões socialmente contextualizadas, tais como as representações sociais da profissão, o estatuto técnico e teórico da profissão, e o desenvolvimento da competência necessária para exercê-la. Assim, a experiência subjetiva pessoal vinculou-se a elementos do contexto social, oferecendo a conscientização de uma subjetividade social imbricada permanentemente com os contextos sociais, culturais e históricos em que os participantes se encontram.

A percepção dos benefícios, segundo relatado nas avaliações de reação, referiu-se à mudança de perspectiva em relação a si mesmo, maior consciência dos próprios sentimentos em relação às suas circunstâncias e a ocorrência de reflexões que podem ajudar na tomada de decisões importantes em relação à própria vida. A oportunidade de situar-se numa realidade social mais ampla parece oferecer um antídoto ao sentimento de excessivo isolamento individual.

Os temas relacionados com o "Lá" (sociedade, expectativas sociais) e "Agora" (o momento de transição vivido pelos participantes), tal como proposto por Hopper (2003), ganharam espaço nas discussões realizadas nos encontros. Embora não se possa dizer que elementos sociais inteiramente inconscientes tenham emergido, evidencia-se que aspectos fracamente percebidos receberam realce e, consequentemente, propiciaram para os participantes, consciência mais clara e reflexão mais profunda sobre as circunstâncias vividas.

\section{Apreciação da Experiência à Luz das Hipóteses de Trabalho Utilizadas pelos Teóricos do Sonhar Social}

1) Nossa experiência tende a confirmar a hipótese de que é possível "sonhar socialmente", mediante a realização bem sucedida da sequência processual que caracteriza o sonhar social: a) compartilhamento de sonhos individuais, b) associações livres dos participantes, c) estabelecimento de conexões entre sonhos, d) identificação de padrões, e) emergência de significados sociais (Gui, 2010).

2) A matriz revelou-se como um continente sui generis para receber sonhos, oferecendo uma nova maneira de pensar sobre o sonhar: os participantes se envolveram no jogo de narrativas e associações recíprocas, suspendendo eventuais atitudes interpretativas voltadas para explicar o psiquismo individual. Parece ter se desenvolvido nos encontros uma aprendizagem sobre a maneira de lidar com os sonhos apresentados, com vistas à explicitação do nexo social embutido nos sonhos.

3) A hipótese de que na matriz os sonhos deixam de ser posse individual se fortalece, uma vez que os participantes se permitiram fazer associações livremente, sem negar ou rejeitar associações feitas com seus próprios sonhos. Ao contrário, os participantes de ambos os grupos manifestaram compreensão e adesão à regra "associar-conectar-descobrir nexos".

4) É difícil afirmar que os encontros tenham possibilitado o surgimento de elementos totalmente inconscientes para os participantes. Alguns dos intercâmbios sugerem que, pelo menos, certos aspectos do inconsciente social (Fromm et al., 1970; Hopper, 2003) ganharam realce no diálogo reflexivo sobre os sonhos. No Grupo Psi notou-se a emergência de aspectos vivenciais e circunstanciais até então pouco percebidos pelos participantes, a ponto de serem valorizados por eles como verdadeiros insights.

5) A mobilização da capacidade de pensar dos participantes conduziu à apreensão de novos padrões de fatos, mediante a "garimpagem" de significados no emaranhado de associações que emergiram.

6) 6. A matriz possibilitou aos participantes a experiência de permanecer no desconhecido, suportando dúvidas, mistérios e incertezas. Durante a narrativa dos sonhos e subsequente processo associativo e amplificador de temas, não se sabia ainda a que resultados se chegariam. A primeira etapa do trabalho (compartilhamento de sonhos, associações etc.), em decorrência da qualidade lúdica, favoreceu a espontaneidade e, consequentemente, facilitou a tolerância de aspectos desconhecidos e nebulosos que emergiram da associação livre. Esperava-se que o diálogo reflexivo sobre os sonhos pudesse suscitar ansiedades diante da tarefa incerta de busca de significados sociais. Nos encontros do Grupo Gestão não surgiram ansiedades excessivas nessa etapa do trabalho, revelando que os participantes exercitaram a tolerância diante do incerto e duvidoso, critério importante de saúde psicológica na acepção de Bion (Grotstein, 2010). Podemos dizer o mesmo do Grupo Psi, embora depoimentos na avaliação de reação tenham denotado a emergência de ansiedades relacionadas a questões psicológicas individuais.

7) O primeiro corpus ofereceu evidências mais incisivas sobre o potencial dos sonhos como fonte de criatividade e solução de problemas. Diante da apresentação de um sonho-atrator (conforme definido), que fazia referência a uma vivência de aprisionamento na organização, na forma de uma gaiola, surgiu a imagem da criação de uma janela. Embora essa imagem não seja propriamente uma solução, poderia vir a sofrer novas transformações, sugerindo caminhos para se lidar com o dilema trabalhado pelo grupo: "como ser criativo diante de um contexto organizacional restritivo". No segundo corpus, podemos perceber evidências de "soluções psicológicas" surgidas da narrativa dos sonhos, tal como é usual acontecer em processos psicoterapêuticos: por exemplo, sonhos e associações que 
remeteram a uma mudança na atitude da sonhadora em relação a sua família e à necessidade de uma atitude psicologicamente mais agressiva para enfrentar os desafios da vida. O potencial solucionador de problemas dos sonhos narrados na matriz poderia ser mais bem identificado nos subsequentes desdobramentos práticos da matriz, no caso do contexto organizacional ao qual pertence o primeiro grupo, e no contexto familiar e profissional, no caso do segundo. A hipótese poderá ser fortalecida com a realização, em estudos futuros, de uma quantidade maior de encontros, possibilitando a emergência de soluções relacionadas com o contexto vivido pelos participantes.

8) O primeiro corpus ofereceu exemplos de situações nas quais elementos transferenciais surgem tendo como objetos, inicialmente, colegas de trabalho e participantes e, a seguir, as imagens dos sonhos. Parece que a situação configurada pela matriz favoreceu a convergência de elementos transferenciais para as imagens oníricas, tal como afirma Lawrence (2003). No Grupo Psi apareceram indícios transferenciais em relação à figura do facilitador que, no entanto, não foram interpretados na perspectiva psicológica individual, mas no sentido do papel social (psicólogo) representado por ele. Embora o enquadre da matriz do sonhar social possibilite certa contenção para fenômenos transferenciais, seria interessante observar o que aconteceria num esquema de encontros mais frequentes. Talvez esses fenômenos viessem a se acirrar, exigindo uma intervenção interpretativa em moldes mais psicoterapêuticos. Mais investigações a esse respeito são necessárias.

9) A matriz do sonhar social parece ter se apresentado como um fenômeno transicional (Balamuth, 2003; Szekacs, 2003) que facilitou a conversão do sonho experienciado subjetivamente em realidade objetiva. A experiência dos participantes do primeiro grupo sugere que a matriz do sonhar social possibilita a constituição de um espaço cultural de reflexão, discussão e de possíveis propostas de intervenção sobre a realidade compartilhada. No segundo grupo, surgiram evidências semelhantes desse espaço transicional, sintetizadas na fala de um dos participantes: "[a matriz oferece] oportunidade de me situar diante de uma realidade maior que é a social, saindo do isolamento individual". Podemos supor que a experiência de trabalhar em uma ambiência de pensar onírico possibilita ao indivíduo uma aprendizagem que o auxiliará a produzir mudanças nos diversos âmbitos de sua vida, abrindo aqui uma perspectiva para o uso do sonhar social com finalidades psicoterapêuticas.

Quando cotejamos o esquema de trabalho adotado com os grupos, constatamos a congruência com alguns dos preceitos da pesquisa-ação propostos por Barbier (2004): a tomada de consciência de questões críticas vividas pelo grupo, o compartilhamento das informações obtidas durante o trabalho, a análise e interpretação resultante do trabalho reflexivo, a linguagem utilizada nesse compartilhamento, análise e interpretação pelo próprio grupo. A etapa que finalizaria uma estratégia de pesquisa-ação, qual seja, a de possibilitar à comunidade pensar em estratégias de ação transformadoras da realidade psicossocial, não ocorreu em nosso experimento. Mas, apesar do trabalho não ter prosseguido até o ponto de aplicação das descobertas feitas pelos grupos, tudo indica que o material emergente poderá oferecer importantes insights, tanto para eventuais diagnósticos quanto para estratégias de intervenção psicossocial em ambiente organizacional, no caso do primeiro grupo, bem como para projetos de vida pessoais e profissionais, no caso do segundo grupo, conforme indicado por depoimentos na avaliação de reação dos encontros do Grupo Psi.

\section{Considerações sobre a Utilização do Sonhar Social em Processo de Intervenção Psicológica}

A vivência na matriz do sonhar social, além de propiciar novas perspectivas sobre a realidade social vivida pelos participantes, parece ter oferecido benefícios pessoais, tais como, mudanças na percepção de si mesmo e maior consciência em relação aos próprios sentimentos suscitados pelas circunstâncias de vida, segundo declarações dos participantes.

Outro aspecto promissor do dispositivo refere-se ao exercício da capacidade pessoal de permanecer durante certo tempo - o tempo vivenciado na matriz - na incerteza, dúvida e obscuridade do universo onírico que se instala no trabalho. Tal aspecto - a "capacidade negativa" (negative capability) - é frequentemente evocada por Bion como característica da atuação efetiva do analista, expressa na capacidade emocional de contenção, "sem memória e sem desejo" (Bion, 1970/2006b, p. 47), que liga elementos aparentemente não relacionados entre si em uma série de associações livres (Grotstein, 2010) e evita a precipitação em explicações imediatas e generalistas. Navegar pelo universo associativo criado pelo grupo, buscar regularidades e identificar temas sociais significativos para a vida dos participantes é um exercício de tolerância à frustração diante daquilo que ainda não está dado e que se encontra em estado nascente. Podemos conjeturar sobre os efeitos que tal exercício continuado poderá suscitar no desenvolvimento das capacidades psíquicas das pessoas que se disponham a participar de encontros do sonhar social. Da mesma forma, podemos pensar sobre a potencialização de processos psicoterapêuticos individuais ou grupais quando acompanhados por tais encontros, em saúde, ou em processos educacionais, com crianças da pré-escola, por exemplo, tal como relata Balamuth (2003).

\section{Considerações Finais}

O trabalho na matriz do sonhar social foi percebido como produtivo e propiciador de novas perspectivas sobre a realidade social dos participantes. A tarefa - narrar sonhos, fazer associações, estabelecer ligações entre sonhos, encontrar nexos e atribuir significado social - bem como a "regra fundamental" - evitar interpretações psicológicas, biográficas 
ou relacionadas à dinâmica psicológica do grupo - foram facilmente compreendidas.

Embora o trabalho na matriz busque eludir o processo transferencial em relação ao facilitador e entre os participantes, convergindo-o para os sonhos, outras investigações serão necessárias para a análise da eventual emergência de fenômenos transferenciais (e contra- transferenciais) e da maneira de lidar com tais ocorrências, sobretudo em grupos que funcionem por períodos mais extensos do que os utilizados neste estudo.

A experiência com o Grupo Gestão confirma o potencial da matriz do sonhar social e de seu complemento - o diálogo reflexivo sobre os sonhos - como dispositivo efetivo para a explicitação de situações sociais atuais e para a geração de ideias embrionárias que podem ser utilizadas para o desenvolvimento futuro do sistema em questão, confirmando a funcionalidade da matriz do sonhar social como dispositivo de pesquisa-ação.

Embora não pudéssemos saber de antemão quais aspectos da realidade social seriam constelados, parece-nos que as circunstâncias mais próximas aos participantes tiveram sua emergência favorecida, o que confirma a hipótese central da matriz do sonhar social: questões da vivência social dos participantes surgem no processo associativo e na elaboração reflexiva sobre os sonhos.

O conceito de "sonho-atrator" emergiu no presente estudo como consequência da observação de que certos sonhos apresentam intensa atração associativa para os participantes. Algumas das características do sonho-atrator são: torna-se foco de atenção dos participantes, atrai grande quantidade de associações, favorece conexões com outros sonhos, catalisa o processo de conexão das associações com as circunstâncias vivenciais comuns aos participantes, favorece a construção de um sentido compartilhado pelo grupo e, por último, apresenta a tendência de ter suas imagens incorporadas ao "idioma" do grupo; em suma, um quase "grande sonho" das culturas tradicionais.

As hipóteses de trabalho com as quais os pesquisadores do sonhar social têm trabalhado recebem, de maneira geral, apoio de nosso estudo. Cogitamos mais uma hipótese de trabalho, relacionada à possível utilização do sonhar social na intervenção psicológica, que pode ser assim formulada: "A prática do sonhar social favorece o desenvolvimento da 'capacidade negativa', e assume um caráter sinérgico nas intervenções clínicas psicoterapêuticas e psicossociais". Desenhos de pesquisa que contemplem a articulação de dispositivos psicoterapêuticos (sessões de psicoterapia individual ou grupal, por exemplo), ou psicossociais, com encontros de sonhar social possibilitarão a investigação da mútua influência dessas estratégias.

\section{Referências}

Amitzi, V. (2007). Life in Israel 1988-2004: associations, thoughts and reflections on social dreaming. In W. G. Lawrence (Ed.), Infinite possibilities of social dreaming (pp. 46- 64). Londres: Karnac Books Ltd.
Barbier, R. (2004). A pesquisa-ação. (L. Didio, Trad.). Brasília: Liber Livro Editor. (Trabalho original publicado em 2002)

Bauer, M. (2002). Análise de conteúdo clássica: uma revisão. In Bauer, M. W. \& Aarts, B. (Eds.) Pesquisa qualitativa com texto, imagem e som. Um manual prático (pp. 189-217 ). (P. A. Guareschi, Trad.). Petrópolis, RJ: Vozes. (Trabalho original publicado em 2000).

Bauer, M. W., \& Aarts B. (2002). A construção do corpus: um princípio para a coleta de dados qualitativos. In M. W. Bauer \& G. Gaskell (Eds.). Pesquisa qualitativa com texto, imagem e som. Um manual prático (pp. 39-63) (P. A. Guareschi, Trad.). Petrópolis, RJ: Vozes. (Trabalho original publicado em 2000)

Bion, W. R. (2006a). Experiencias en grupos. Buenos Aires: Paidós. (Trabalho original publicado em 1963)

Bion, W. R. (2006b). Atenção e interpretação. (P. C. Sandler, Trad. $2^{\mathrm{a}}$ ed.) Rio de Janeiro: Imago. (Trabalho original publicado em 1970)

Balamuth, R. (2003). Childreamatrix: dreaming with preschool children - or, boothegging dreams into the school years. In W. G. Lawrence (Ed.), Experiences in social dreaming (pp. 122-141). Londres: Karnac.

Fromm, E., Suzuki, D. T., \& De Martino, R. (1970). Zen budismo e psicanálise. (O. M. Cajado, Trad.). São Paulo: Cultrix. (Trabalho original publicado em 1960)

Grotstein, J. S. (2010). Um facho de intensa escuridão. O legado de Wilfred Bion à psicanálise (M. C. Monteiro, Trad.). Porto Alegre: Artmed. (Trabalho original publicado em 2007)

Gui, R. T. (2010). Matriz do sonhar social: um dispositivo de intervenção em psicologia clínica. Tese de Doutorado, Universidade de Brasília, Brasília.

Hopper, E. (2003). The social unconscious. Selected papers. London: Jessica Kingsley Publishers.

Laville, C., \& Dionne, J. (1999). A construção do saber. Manual de metodologia da pesquisa em ciências humanas. (H. Monteiro \& F. Settineri, Trad.). Belo Horizonte: Ed. UFMG. (Trabalho original publicado em 1997)

Lawrence, W. G. (1991). Won from the void and formless infinite: Experiences of social dreaming. Free Associations, 2 (part 2, $\left.n^{\circ} 22\right):$ 254-266.

Lawrence, W. G. (Ed.) (1998a). Social dreaming@work. London: Karnac Books.

Lawrence, W. G. (1998b). Social dreaming as a tool of consultancy and action research. In W. G. Lawrence (Ed.), Social dreaming (a) work (pp. 123-140). London: Karnac Books.

Lawrence, G. (Ed.) (2003). Experiences in social dreaming. London: Karnac.

Lawrence, W. G. (2005). Introduction to social dreaming. Transforming thinking. London: Karnac Books.

Lawrence, W. G. (Ed.) (2007a). Infinite possibilities of social dreaming. London: Karnac Books.

Lawrence, W. G. (2007b). Dream reflection group. In W. G. Lawrence (Ed.), Infinite possibilities of social dreaming (pp. 162-166). London: Karnac Books.

Marinelli, S., Girelli, R. (2007). Icons of the social dream: experiences at the University of L'Aquila, Italy. In W. G. Lawrence (Ed.), Infinite possibilities of social dreaming (pp. 91-105). Londres: Karnac Books Ltd. 
Michael, T. A. (1998). The use of dreams in systems-centred theory. In W. G. Lawrence (Ed.), Socialdreaming@work (pp. 59-68). London: Karnac Books.

Michael, T. A. (2007). You must not be dreaming: how social dreaming may help us wake up. In W. G. Lawrence (Ed.), Infinite possibilities of social dreaming (pp. 120-130). Londres: Karnac Books Ltd.

Morgan, H. (2007). Shedding light on organizational shadows. In Lawrence, W. G. (Ed.), Infinite possibilities of social dreaming (pp. 106 - 112). Londres: Karnac Books Ltd.

Moura, M. L. S., \& Ferreira, M. C. (2005). Projetos de pesquisa. Elaboração, redação e apresentação. Rio de Janeiro: Eduerj.

Neri, C. (2003). Social dreaming: report on the workshops held in Mauriburg, Raissa, and Clarice Town. In W. G. Lawrence (Ed.), Experiences in social dreaming (pp. 15-35). Londres: Karnac.

Sievers, B. (2007). There is nothing more worth fighting for: social dreaming with social democrats in Austria. In W. G. Lawrence (Ed.), Infinite possibilities of social dreaming (pp. 18-28). Londres: Karnac Books Ltd.

Szekacs, J. (2003). Social dreaming: a paradox accepted (a psychoanalyst's condensed thoughts on social dreaming). In W. G. Lawrence (Ed.), Experiences in social dreaming (pp. 246-251). Londres: Karnac.
Tedlock, B. (1987). Dreaming and dream research. In B. Tedlock (Ed.), Dreaming. Anthropological and psychological interpretations (pp. 1-30). Cambridge (UK): Universidade de Cambridge.

Tedlock, B. (1991). The new anthropology of dreaming. Dreaming. Journal of the Association for the Study of Dreams, 1(2), Retrieved from http://www.asdreams.org/journal/articles/12tedlock1991.html. 


\section{ANEXO A - Avaliação de reação parcial dos encontros do sonhar social}

Gostaríamos de contar com sua avaliação sobre a experiência de ter participado dos dois primeiros encontros. Por favor, responda às questões abaixo:

1) Lembra-se de ter sonhado na noite anterior aos encontros? Você associa o fato de ter sonhado com a expectativa de participar do encontro? Comente por favor.

2) Sentiu-se à vontade para apresentar seus sonhos? Comente, por favor.

3) Sentiu-se à vontade para fazer associações com os sonhos narrados por você ou pelos demais participantes? Comente, por favor.

4) Como se sentiu ao ouvir associações feitas por outros participantes a respeito de seu(s) sonho(s)?

5) Para você, quais foram os assuntos importantes que surgiram nos encontros. Comente, por favor.

6) Você acredita que as ideias e sentimentos que surgiram nos encontros possam ajudá-lo(a) a pensar sobre mudanças em sua vida? Quais?

7) De que maneira o coordenador facilitou ou dificultou o trabalho nos encontros?

8) Seus comentários adicionais são importantes para o aperfeiçoamento desse trabalho. Fique à vontade para fazê-los. Muito obrigado!

Nome do participante:

\section{ANEXO B - Avaliação de reação final dos encontros do sonhar social}

Gostaríamos de contar com sua avaliação final sobre a experiência de ter participado dos Encontros do Sonhar Social. Por favor, responda às questões abaixo:

1) À medida que os encontros ocorreram, ficou mais fácil para você lembrar de seus sonhos? Comente, por favor.

2) À medida que os encontros ocorreram, ficou mais fácil ou mais difícil fazer associações com os sonhos apresentados? Comente, por favor.

3) Quais foram os assuntos importantes que surgiram nos encontros. Comente, por favor.

4) Você acredita que as ideias e sentimentos que surgiram nos encontros possam ajudá-lo(a) a pensar sobre mudanças em sua vida? Quais?

5) Os encontros do sonhar social trouxeram alguma contribuição para sua vida pessoal? Comente por favor.

6) Seus comentários adicionais são importantes para o aperfeiçoamento desse trabalho. Fique à vontade para fazê-los. Muito obrigado!

Nome do(a) participante: 